\title{
Performance Comparison of Evolutionary Algorithms in the Design of a Hand-Pump Shape Microstrip Antenna for 5G Applications
}

\author{
Navneet Kaur*, Surbhi Sharma, Jaswinder Kaur \\ Electronics and Communication Engineering Department, \\ Thapar Institute of Engineering and Technology, \\ Patiala, India \\ navneet_kaur@thapar.edu
}

\begin{abstract}
In this work, a single element hand-pump shape microstrip patch antenna working at $3.4 \mathrm{GHz}-3.8 \mathrm{GHz}$ for future 5G applications is proposed. The overall dimensions of the proposed antenna are $34 \mathrm{~mm} \times 28 \mathrm{~mm} \times 1.6 \mathrm{~mm}$. In order to obtain the desired bandwidth, three rectangular slots are etched from the radiating element along with the utilization of the defected ground structure. To optimize the geometrical parameters of the proposed antenna, performance comparison of various optimization techniques viz. Particle Swarm Optimization, Bat algorithm, Differential Evolution, and Artificial Bee Colony algorithm are presented. The performance of the antenna is analyzed with the help of $S$ parameter, gain, and radiation efficiency. The proposed antenna is resonant at $3.6 \mathrm{GHz}$ with an impedance bandwidth of $400 \mathrm{MHz}$ and the radiation efficiency of $74 \%$, which is quite appropriate for a single element 5G antenna. Further, the suggested antenna is fabricated and experimentally tested for the validation of results.
\end{abstract}

Index Terms-Artificial bee colony algorithm; Bat; Differential evolution; Fifth generation.

\section{INTRODUCTION}

$5 \mathrm{G}$ is an upcoming generation of the cellular standards for wireless communication. Different research groups like Ericsson, Huawei, Qualcomm, and many more have already started their work towards 5G technology, its standards and frequency spectrum [1].Due to the early stage of commercial $5 \mathrm{G}$ system deployment, it can support only three frequency ranges, i.e., below $1 \mathrm{GHz}$, sub-6 GHz, and millimeter wave bands. The low bands below $1 \mathrm{GHz}$ are identified to provide the deep indoor penetration for massive internet of things (IoT) connectivity. The mid-range band of sub- $6 \mathrm{GHz}$ is recognized to provide dense area coverage for the enhanced mobile broadband services. On the other hand, the higher mm-wave bands inherit characteristics like short wavelength and high bandwidth. Therefore, they can be used for extreme bandwidths and higher data rates for the short-range applications, such as a mobile hotspot. Presently, from the sub- $6 \mathrm{GHz}$ spectrum, $3.4 \mathrm{GHz}-3.8 \mathrm{GHz}$ band is gaining a lot of attention. It is the combination of a long-term evolution (LTE 42$)$ band $(3.4 \mathrm{GHz}-3.6 \mathrm{GHz})$ and LTE 43 $(3.6 \mathrm{GHz}-3.8 \mathrm{GHz})$. The band is identified by many

Manuscript received 23 December, 2018; accepted 8 August, 2019. countries as a pioneer to realize the $5 \mathrm{G}$ technologies like massive MIMO arrays and antennas. For example, the European Union (EU) preferentially develops the $3.4 \mathrm{GHz}-$ $3.8 \mathrm{GHz}$ band, while China is investigating the $3.4 \mathrm{GHz}-$ $3.6 \mathrm{GHz}$ band as a $5 \mathrm{G}$ sub- $6 \mathrm{GHz}$ band. Korea selects the $3.4 \mathrm{GHz}-3.7 \mathrm{GHz}$ band for its preliminary study also. In addition to that, it is allocated for the global broadband services and can be used with the existing technologies 3G/WIMAX/Wi-Fi/LTE with some minor changes [2].

In recent literature [3]-[10], different antenna configurations, such as single element antennas, multipleinput multiple-output (MIMO) antennas and arrays have been reported for the $5 \mathrm{G}$ applications. In works [3]-[6], the research is focused towards a single element antenna and array design at mm-waves, such as $28 \mathrm{GHz}, 38 \mathrm{GHz}$, and $60 \mathrm{GHz}$. These higher bands can provide high data rates of up to $20 \mathrm{Gbps}$ and extreme hotspot capacity. Still, the atmospheric losses at these bands are the major issue and, therefore, these kind of antennas are not suitable for a long distance communication. To account for different propagation attributes in these mm-wave bands, the design and implementation of on-chip antennas are presented in [11]-[13]. However, on-chip antennas suffer from low resistivity, high dielectric constant substrate, low gain $(3.8 \mathrm{dBi}$ at $30.5 \mathrm{GHz})$ [11], and poor radiation efficiency [12], which are the major issues in $\mathrm{mm}$-wave $5 \mathrm{G}$ antennas. Although there are several ways to increase the efficiency of on-chip antennas by post-fabrication techniques, they are expensive for mass production [13]. Hence, planar printed antennas are good option pertaining to $5 \mathrm{G}$ applications below sub- $6 \mathrm{GHz}$ and mm-wave bands.

In [7], a single element planar circularly polarized 5G antenna is designed for the S-band $(3.6 \mathrm{GHz}-4 \mathrm{GHz})$ applications. In the designed antenna, thickness is very high of the order of $27 \mathrm{~mm}$ and the complete range of S-band ( $2 \mathrm{GHz}$ to $4 \mathrm{GHz}$ ) is not covered.

Furthermore, MIMO antennas at sub-6 GHz band to increase the radiation performance of the antennas are also being reported in literature [8]-[10]. A dual band ten element MIMO antenna is proposed at LTE $42 / 43(3.4 \mathrm{GHz}$ $-3.8 \mathrm{GHz})$ and LTE $46(5.15 \mathrm{GHz}-5.925 \mathrm{GHz})$ for sub$6 \mathrm{GHz} 5 \mathrm{G}$ applications [8]. The designed antenna exhibits a bandwidth of $200 \mathrm{MHz}$ at a lower band of LTE with the 
radiation efficiency of 42-62\%. Whereas at a higher band of LTE, bandwidth of $770 \mathrm{MHz}$ (below $-6 \mathrm{~dB}$ ) with the radiation efficiency of $62-82 \%$ is obtained. The efficiency of the lower band (LTE 42) is quite low and and the whole band is not being covered with the reference of $-10 \mathrm{~dB}$ impedance bandwidth. In [9], a decoupled eight element MIMO antenna is designed covering two bands $3.5 \mathrm{GHz}$ and $5.8 \mathrm{GHz}$. It is designed to obtain a bandwidth of $200 \mathrm{MHz}$ at $3.5 \mathrm{GHz}$, which is the same as in [8] and $150 \mathrm{MHz}$ at $5.8 \mathrm{GHz}$, which is very less as compared to [8] with the radiation efficiency of $55 \%$ and $70 \%$, respectively. Moreover, the required bandwidth of $5 \mathrm{G}$ spectrum, which is $400 \mathrm{MHz}$, is not being covered with reference of $-10 \mathrm{~dB}$ impedance bandwidth in [8]-[10] also. To cover the minimum bandwidth of $5 \mathrm{G}$ spectrum, a four element MIMO antenna is designed on an FR4 substrate of $50 \times 50 \times$ $0.8 \mathrm{~mm}^{3}$ with $4 \mathrm{dBi}$ measured gain for sub- $6 \mathrm{GHz} 5 \mathrm{G}$ applications [10]. However, the size of the antenna is very large for future generation applications.

In the above-discussed literature [7]-[10], single element and MIMO antennas are designed for sub- $6 \mathrm{GHz} 5 \mathrm{G}$ band to improve the antenna performance parameters, such as bandwidth, gain, and radiation efficiency of the antenna for $5 \mathrm{G}$ applications. However, the structures of antennas occupy a much larger space, smaller operational bandwidth, and poor radiation efficiency. Therefore, the main driving force in writing this research paper is to obtain smaller size, higher bandwidth, and radiation efficiency at LTE 42/43 (3.4 GHz-3.8 GHz ) band for $5 \mathrm{G}$ applications. In addition to that, the optimization for a single element patch antenna for sub- $6 \mathrm{GHz} 5 \mathrm{G}$ applications has not been reported in literature. Thus, our work is focused towards the optimization of geometrical parameters of a single element microstrip patch antenna (MPA) for $5 \mathrm{G}$ sub- $6 \mathrm{GHz}$ band.

To accomplish better antenna performance results with the optimized geometrical parameters of antenna performance, a comparison of the recent evolutionarily algorithms, such as Particle Swarm Optimization (PSO) [14], Differential Evolution (DE) [15], Artificial Bee Colony $(\mathrm{ABC})$ [16], and Bat [17] is done with a respect to mean, standard deviation, and the best cost value. Although a similar comparison is available to optimize the spacing between circular patches in [17] and [18], but it is not considered for optimizing the individual geometrical parameters of a single band antenna. Further, the reported analysis is not extended to recent optimization techniques like Bat and $\mathrm{ABC}$. It is also ensured that the comparison is made with all algorithms working nearly at their best by tuning all control parameters for impedance matching of the $5 \mathrm{G}$ application antenna. The proposed antenna geometry is resembled to a hand-pump shape that gives the broad bandwidth as compared to the basic rectangular shape of antenna. Two rectangular slots are etched from the ground plane of the antenna to attain the characteristics of the defected ground structure (DGS). The hand-pump shape microstrip patch antenna (MPA) antenna is designed using a commercially available three-dimensional simulation software Computer Simulation Technology Microwave Studio Version (CST). Our work is bifurcated into four Sections (Section II-Section VII) to give a detailed overview regarding details of the antenna design, a comparison of different optimization algorithms, implementation of the best algorithm, and optimized results used for fabrication and measurement results, respectively.

\section{ANTENNA DESIGN DETAILS WITHOUT OPTIMIZATION}

The proposed planner antenna draws inspiration from conventional rectangular patch, which is further modified to the structure of a hand-pump shape single band antenna. In order to better understand the antenna design process, it is further demonstrated with the three stages of antenna geometry. The initial stage of the antenna is shown in Fig. 1(a), which resonates at $4.18 \mathrm{GHz}$ with an operational bandwidth of $288 \mathrm{MHz}$, which is quite wider than basic rectangular patch antenna. The performance of the initial stage is not adequate in terms of desired frequency band, bandwidth, and S-parameter for 5G application. Therefore, to obtain the appreciable performance characteristics without affecting the overall size of the antenna, the initial antenna design is modified by embedding rectangular slots in the ground plane at the intermediate stage as shown in Fig. 1(b). In the given stage, the resonant frequency is shifted from $4.18 \mathrm{GHz}$ to $3.51 \mathrm{GHz}$ with an impedance bandwidth of $724 \mathrm{MHz}$. The performance of $\mathrm{S}_{11}$ is also being improved with respect to the initial stage viz. $25.3 \mathrm{~dB}$. Further, to attain the desired sub- $6 \mathrm{GHz}(3.4 \mathrm{GHz}-$ $3.8 \mathrm{GHz}$ ) frequency band, the antenna structure in the intermediate stage is modified by etching a rectangular slot near the feed line. The technical insertion of the rectangular notch in the patch near the feed line is responsible to reject the undesired band. In addition to that, it is added to alter the current distribution of the radiating element. The final stage of the antenna is depicted in Fig 1(c), which shows an impedance bandwidth of $230 \mathrm{MHz}$ with resonating frequency at $3.57 \mathrm{GHz}$ and $\left|\mathrm{S}_{11}\right|$ of $-19.26 \mathrm{~dB}$.
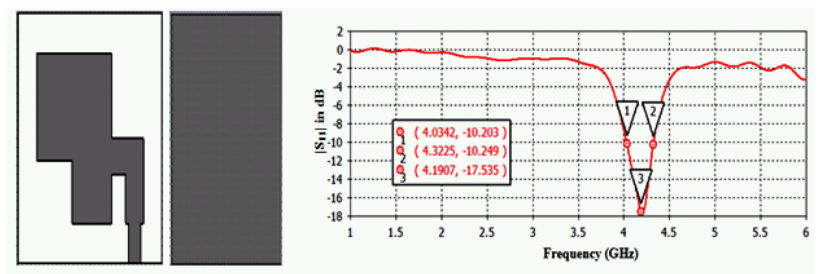

(a)
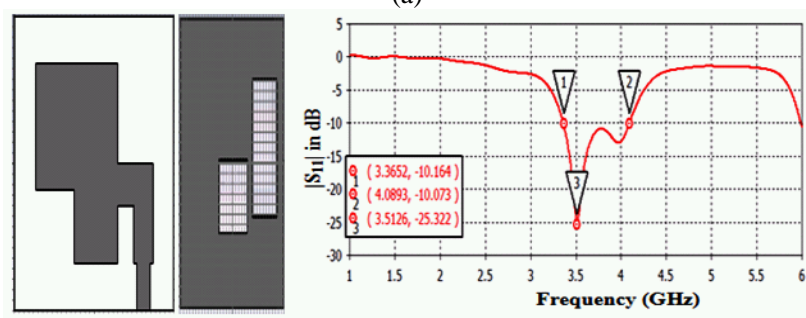

(b)
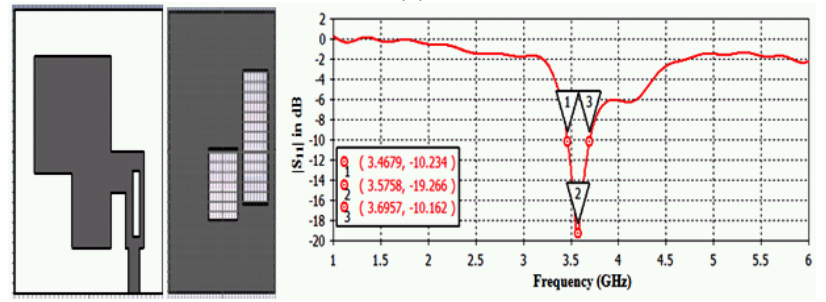

(c)

Fig. 1. Different stages of hand-pump shape MPA with front view, back view, and corresponding $\left|S_{11}\right|$ graph.: (a) Initial stage; (b) Intermediate stage; (c) Final stage. 
In addition to the S-parameter, the gain is also important to analyze the radiation performance of the antenna. Figure 2 shows the plot of the peak gain versus the frequency for the final stage of non-optimized hand-pump shape MPA.

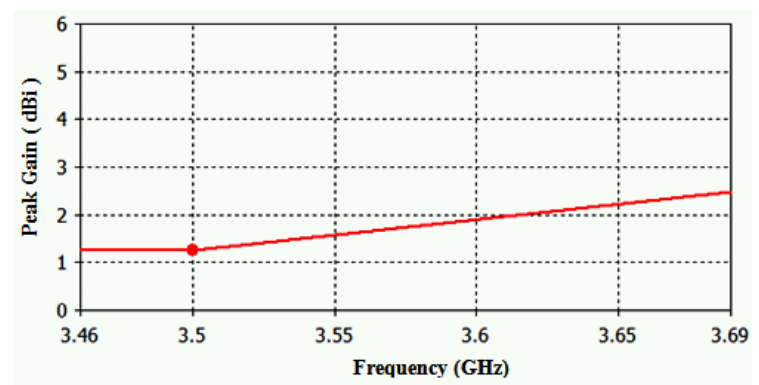

Fig. 2. Simulated peak gain for the final stage of non-optimized handpump shape MPA.

The peak gain is obtained as $2.39 \mathrm{~dB}$ for the frequency ranging from $3.46 \mathrm{GHz}-3.69 \mathrm{GHz}$. The simulation results discussed in Fig. 1 and Fig. 2 with respect to $\left|S_{11}\right|$ parameter and gain does not match the requirements of the mid-range of 5G standards. Thus, the optimization of the antenna parameters needs to be done in order to attain the desired frequency band with good impedance matching and better antenna radiation performance.

\section{PERFORMANCE COMPARISON OF ALGORITHMS}

The optimization techniques, such as PSO, DE, Bat, and $\mathrm{ABC}$ are applied for the optimization of a hand-pump shape 5G MPA to find out the best algorithm for solving our problem. The optimization process is carried out on a personal laptop having Intel i5 processor and 6 GB RAM. The fitness function of the problem for the antenna design is defined (in MATLAB) using transmission line model equation of MPA in such a way that antenna must be impedance matched over a desired frequency band $(3.4 \mathrm{GHz}-3.8 \mathrm{GHz}$ ) below $-40 \mathrm{~dB}$ return loss. The used fitness function can include the other fundamental parameters of the antenna, such as gain, radiation pattern, and efficiency that lead to a multi-objective function. However, multi-objective functions have many drawbacks like increased computer system requirements with more number of iterations. In order to avoid these difficulties, the most important impedance matching parameter of the antenna design, i.e., $\left|S_{11}\right|$, is used as an objective function to optimize the single band hand-pump shape MPA. For the optimized simulation purpose, the population size and number of iterations are kept the same for all the algorithms. The population size is kept thrice the number of individual parametric length of the antenna in each algorithm and simulation is carried out for 250 iterations. The particular control parameters for different optimization algorithms are tabulated in Table I. All the algorithms are briefly discussed as follows.

PSO: It is motivated by social and mutual activities of a variety of species to fill their needs in the search space. Its performance is based upon the personal experience $\left(\mathrm{P}_{\text {best }}\right)$, overall experience $\left(\mathrm{G}_{\text {best }}\right)$, and the present movement of the randomly generated particles to choose their next positions in the optimization design space. Further, the experiences of the particles are accelerated by two factors $C_{1}$ and $C_{2}$, which are the two random numbers generated between $[0,1]$, whereas the current movement is multiplied by an inertia factor varying between $\left[\mathrm{w}_{\min }, \mathrm{w}_{\max }: 0.4,0.9\right]$.

$D E$ : It is working through the four steps in the search space initialization, mutation, crossover, and selection. In this work, the value of scaling factor (SF) is defined as 0.6 and the value of crossover (CR) is defined as 0.4.

Bat: It is based on the echolocation principle of SONAR. The micro bats emit very short pulse signal and listen for the echo signal that is reflected back from the surrounding objects to detect the optimal solution of the problem. The rate of pulse $\left(\mathrm{Q}_{1}\right)$ and emission of pulse $\left(\mathrm{Q}_{2}\right)$ are defined as 0.9 and the loudness of the sound varies from maximum positive value to minimum value, i.e., $\left(\mathrm{F}_{\max }, \mathrm{F}_{\min }\right.$ : 1,0$)$.

$A B C$ : The $\mathrm{ABC}$ algorithm is divided into three different bee categories named as employed bees $\left(\mathrm{N}_{\mathrm{E}}\right)$, onlooker bees $\left(\mathrm{N}_{\mathrm{O}}\right)$, and scout bees $\left(\mathrm{N}_{\mathrm{S}}\right)$. This optimization algorithm works through three main steps. In the first step, $\mathrm{N}_{\mathrm{E}}$ is searched for the optimal design parameters of the antenna (food source). In the second step, the information of the optimal solution (minimize return loss) is shared with $\mathrm{N}_{O}$. On the basis of this shared information, the $\mathrm{N}_{\mathrm{O}}$ is going to decide to choose the food source. In the third step, if a solution indicating a food source is not revamped by a fixed number of experiments, then is treated as 'limit'. It means that the related food source is exhausted by the bees and the $\mathrm{N}_{\mathrm{E}}$ of this food source becomes $\mathrm{N}_{\mathrm{S}}$. After that, the site of the vacant food source (solution) is replaced with a randomly formed solution [19].

The limit parameter value of the $\mathrm{ABC}$ is defined by using the dimension of the problem and size of the colony as given in the following equation

$$
\text { Limit }=N_{E} \times S
$$

where $\mathrm{S}$ is the dimension of the optimization problem.

The statistical parameters like mean, standard deviation, and cost value are simulated for 15 iterations. As given in Table II, the results show that $\mathrm{ABC}$ renders the lowest mean and standard deviation as compared to the other algorithms. A fitness plot of all the applied algorithms is depicted in Fig. 3. The minimum cost value of the fitness function of the $\mathrm{ABC}$ algorithm clearly indicates that $\mathrm{ABC}$ converges faster as compared to all other algorithms. Thus, the geometrical parameters of the proposed antenna from $\mathrm{ABC}$ algorithm are obtained.

TABLE I. PARTICULAR CONTROL PARAMETERS OF VARIOUS ALGORITHMS FOR PROPOSED MPA.

\begin{tabular}{|c|c|c|c|}
\hline PSO & Bat & DE & ABC \\
\hline $\mathrm{W}_{\text {max }}=0.9$ & $\mathrm{Q}_{1}=0.9$ & $\mathrm{CR}=0.4$ & Limit $=\mathrm{N}_{\mathrm{E}} \times D$ \\
\hline $\mathrm{C}_{1}=2$ & $\mathrm{Q}_{2}=0.9$ & $\mathrm{SF}=0.6$ & $\mathrm{~N}_{\mathrm{E}}=50$ \\
\hline $\mathrm{C}_{2}=2$ & $\mathrm{~F}_{\min }=0$ & & $\mathrm{~N}_{\mathrm{O}}=50$ \\
\hline $\mathrm{W}_{\min }=0.4$ & $\mathrm{~F}_{\max }=1$ & & $\mathrm{~N}_{\mathrm{S}}=1$ \\
\hline
\end{tabular}

TABLE II. PERFORMANCE COMPARISON OF VARIOUS ALGORITHMS FOR PROPOSED MPA.

\begin{tabular}{|c|c|c|c|}
\hline $\begin{array}{c}\text { Optimization } \\
\text { Algorithm }\end{array}$ & $\begin{array}{c}\text { Mean cost } \\
\text { value }\end{array}$ & $\begin{array}{c}\text { Standard } \\
\text { deviation }\end{array}$ & $\begin{array}{c}\text { Best Cost } \\
\text { value }\end{array}$ \\
\hline PSO & 0.0234 & 0.0265 & 0.0811 \\
\hline Bat & 0.0018 & 0.007 & 0.7936 \\
\hline DE & 0.0156 & 0.014 & 0.0559 \\
\hline ABC & 0.0089 & $1.10 \mathrm{e}-5$ & 0.0029 \\
\hline
\end{tabular}




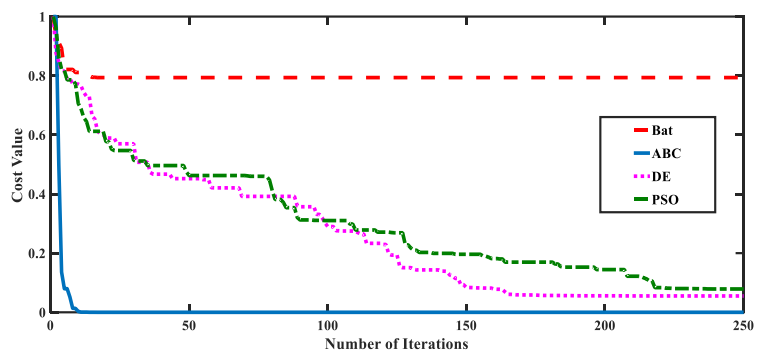

Fig. 3. Normalized best cost value fitness plot of various algorithms.

\section{ANTENNA DESIGN AND SimUlated RESUlts WITH OPTIMIZATION}

The proposed antenna is designed and fabricated using optimized parametric dimensions obtained from ABC algorithm. The front and rear view of a single band handpump shape $5 \mathrm{G}$ antenna is illustrated in Fig. 4. The handpump shape radiating element is printed on the top side and the ground is printed at the bottom side of the Epoxy GlassFR4 substrate having permittivity $\varepsilon_{\mathrm{r}}=4.4$ and loss tangent $\tan \delta=0.0025$, and the thickness of $1.6 \mathrm{~mm}$. The length and width of the ground plane and the substrate is six times length and width of the patch, respectively. The microstrip feedline, which is the least difficult of all the feeding strategies, is utilized as a feeding component for this antenna configuration, which provides decent impedance of $50 \mathrm{ohms}$. In this feeding plan, the edge of the patch is specifically associated with the leading segment of the feedline. This kind of feeding arrangement envelops a planar structure since the feedline and the patch can be manufactured at the same time on a similar substrate, thus lessening the massiveness of the structure of the antenna. The optimized design values of the antenna parameters in mm are: $\mathrm{L}_{\mathrm{p}}=17.5, \mathrm{~W}_{\mathrm{p}}=17, \mathrm{~L}_{1}=10, \mathrm{~L}_{2}=8, \mathrm{a}=7, \mathrm{~b}=2.5, \mathrm{c}$ $=6, \mathrm{~W}_{\mathrm{f}}=1.5, \mathrm{~W}_{\mathrm{p} 1}=19, \mathrm{~S}_{1}=8, \mathrm{~S}_{2}=2.4, \mathrm{~S}_{3}=4.8, \mathrm{~S}_{4}=6.5$, $\mathrm{L}_{\mathrm{g}}=28, \mathrm{~W}_{\mathrm{g}}=34$.

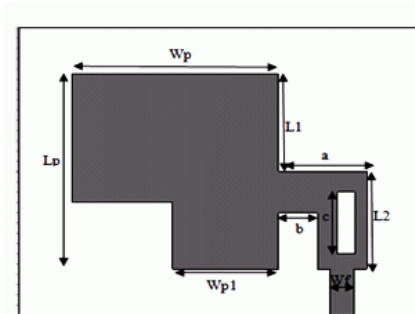

(a)

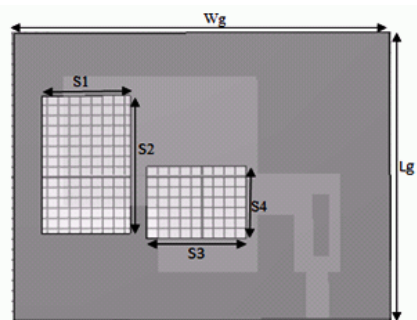

(b)
Fig. 4. Geometrical layout of proposed antenna: (a) Front view; (b) Rear view.

The performance of the proposed antenna in terms of optimized geometrical parameters is inspected on the basis of the simulation results, such as $\left|S_{11}\right|$, gain, and efficiency in the desired frequency range. Figure 5 shows the $\left|S_{11}\right|$ comparison plot of all the optimization algorithms. It is seen that the bandwidth of the antenna is considerably enhanced from $224 \mathrm{MHz}$ in non-optimized antenna as discussed earlier in Fig. 2 to $400 \mathrm{MHz}$ using the $\mathrm{ABC}$ optimization algorithm. Further, it also provides better $\left|\mathrm{S}_{11}\right|=-52.88 \mathrm{~dB}$ near to the desired return loss, i.e., $-40 \mathrm{~dB}$. Figure 6 shows the simulated peak gain of $4.7 \mathrm{dBi}$, which is also enhanced as compared to the non-optimized antenna. Figure 7 depicts the simulated radiation efficiency of the antenna. It is analyzed that radiation efficiency is more than $58 \%$ over the entire frequency band. However, the peak efficiency of the proposed antenna is $74 \%$, which is quite appreciable for a single element $5 \mathrm{G}$ antenna. A comparison of simulated results with and without optimization of the proposed antenna is tabulated in Table III.

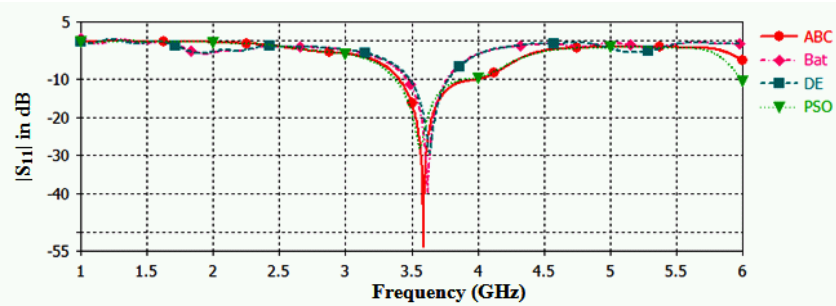

Fig. 5. Simulated $S_{11}$ results for the optimized hand-pump shape MPA with various optimization algorithms.

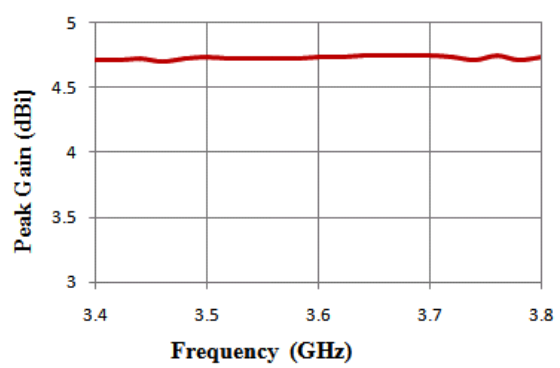

Fig. 6. Simulated peak gain for the optimized hand-pump shape MPA with $\mathrm{ABC}$

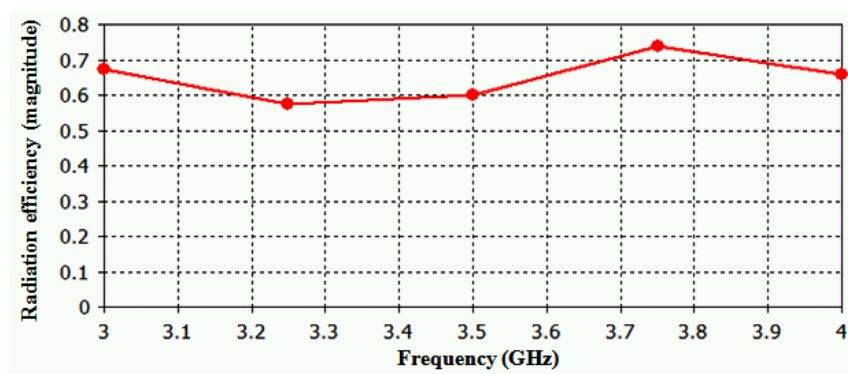

Fig. 7. Radiation efficiency for the optimized hand-pump shape MPA with $\mathrm{ABC}$.

TABLE III. PERFORMANCE PARAMETERS OF PROPOSED ANTENNA WITH AND WITHOUT OPTIMIZATION.

\begin{tabular}{|c|c|c|c|}
\hline $\begin{array}{c}\text { Characteristics } \\
\text { parameters of } \\
\text { proposed } \\
\text { antenna }\end{array}$ & $\begin{array}{c}\text { Operating band } \\
\text { (below -10 dB) }\end{array}$ & $\begin{array}{c}\text { Bandwidth } \\
\text { (below - } \\
\mathbf{1 0 ~ d B})\end{array}$ & $\begin{array}{c}\text { Peak } \\
\text { Gain } \\
\text { (dBi) }\end{array}$ \\
\hline $\begin{array}{c}\text { Without } \\
\text { optimization }\end{array}$ & $3.46 \mathrm{GHz}-3.69 \mathrm{GHz}$ & $230 \mathrm{MHz}$ & 2.3 \\
\hline $\begin{array}{c}\text { With } \\
\text { optimization }\end{array}$ & $3.40 \mathrm{GHz}-3.80 \mathrm{GHz}$ & $400 \mathrm{MHz}$ & 4.7 \\
\hline
\end{tabular}

\section{CURRENT DISTRIBUTION AND FAR-FIELD RADIATION PATTERN}

Figure 8 shows the surface current distribution of the radiating element and the ground plane of the hand-pump shape single band MPA. It can be observed that the current intensity is maximum across the feedline, which is attached to the radiating patch. Two rectangular slots are etched from the ground plane to attain the property of the defected ground structure. The current density is increased near the edge of slots, which means that the inserted slots play a vital role to obtain the desired sub- $6 \mathrm{GHz}$ frequency band $(3.4 \mathrm{GHz}-3.8 \mathrm{GHz})$ without affecting the bandwidth. Figure 
9 illustrates the simulated 3-D radiation pattern of the proposed antenna. It shows the high radiation intensity at a large distance in every direction.

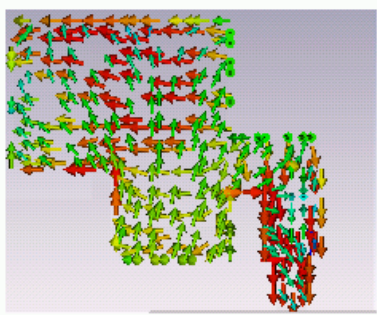

(a)

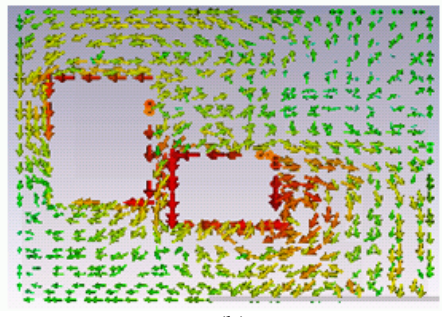

(b)
Fig. 8. Simulated surface current of the proposed antenna at $3.6 \mathrm{GHz}$ : (a) Radiating element; (b) Ground plane.

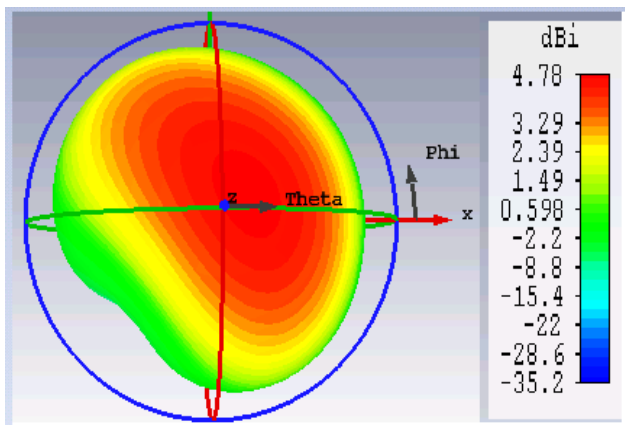

Fig. 9. 3-D Far-field radiation pattern at $3.6 \mathrm{GHz}$.

\section{FABRICATION AND MEASUREMENT RESULTS}

The prototype of the fabricated antenna is illustrated in Fig. 10. The S-parameter of the fabricated antenna is tested using Agilent E 5071C Vector Network Analyzer available at Antenna Research Lab, Electronics and Communication Engineering Department, Thapar Institute of Engineering and Technology, Patiala. The radiation pattern and gain of the fabricated antenna is measured using Anechoic chamber available at Millimeter-Wave and Terahertz Laboratory, Indian Institute of Technology, Roorkee. Figure 11(a) and Figure 11(b) depict a comparison plot of the simulated and measured S-parameter and peak gain of the antenna proposed. It can be observed that the frequency band ranges from $3.4 \mathrm{GHz}$ to $3.8 \mathrm{GHz}$. That is obtained in both the simulated and measured results, but there is a difference between the resonance peak of the $S$-parameter. The resonance peak of the simulated S-parameter is at $-52 \mathrm{~dB}$, whereas the measured resonance peak of S-parameters is at $30 \mathrm{~dB}$ as shown in Fig. 11(b). It may be attributed due to connector losses or minor misalignment of the antenna structure. The simulated peak gain is $4.7 \mathrm{dBi}$ at $3.6 \mathrm{GHz}$ frequency, whereas the measured peak gain slightly drops at each frequency due to the fabrication losses of the antenna as shown in Fig. 11(a). It is observed that $4.6 \mathrm{dBi}$ at $3.6 \mathrm{GHz}$ frequency. The simulated and measured radiation pattern results of the proposed antenna at $3.6 \mathrm{GHz}$ in the E-plane and H-plane are depicted in Fig 12(a) and Fig. 12(b). It is observed that the radiation pattern of E-plane is bidirectional while it is omni-directional for the H-plane, and that helps the antenna to receive the signal from any direction. These properties make it quite appropriate for $5 \mathrm{G}$ applications. Finally, the proposed antenna is compared with the other antennas referred in literature in terms of bandwidth, gain, size, and radiation efficiency as tabulated in Table IV.

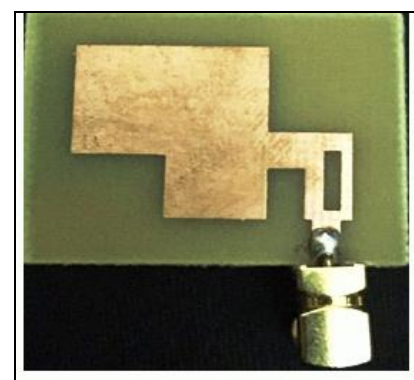

(a)

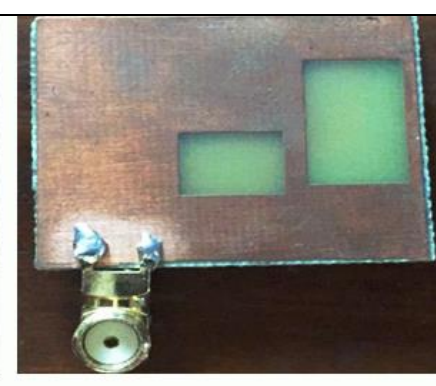

(b)
Fig. 10. Prototype of the fabricated antenna: (a) Radiating element of the antenna; (b) Ground plane.

TABLE IV. COMPARISON OF PRESENT WORK WITH PREVIOUS

\begin{tabular}{|c|c|c|c|c|c|c|}
\hline \multicolumn{7}{|c|}{ WORK. } \\
\hline Ref. & $\begin{array}{c}\text { Ante- } \\
\text { nna } \\
\text { Type }\end{array}$ & $\begin{array}{c}\text { Overal } \\
\text { l } \\
\text { size } \\
\left(\mathbf{m m}^{3}\right)\end{array}$ & $\begin{array}{c}\text { Operat } \\
\text { ing } \\
\text { Band } \\
(\mathbf{G H z})\end{array}$ & $\begin{array}{c}\text { Bandwi } \\
\text { dth } \\
\text { (below- } \\
10 \text { dB) } \\
\text { (MHZ) }\end{array}$ & $\begin{array}{l}\text { Gain } \\
\text { (dBi) }\end{array}$ & $\begin{array}{c}\text { Effi } \\
\text { cien } \\
\text { cy } \\
(\%)\end{array}$ \\
\hline [7] & $\begin{array}{c}\text { Single } \\
\text { Element } \\
\text { MPA }\end{array}$ & $\begin{array}{c}30 \times 30 \\
\times 27\end{array}$ & 3.5 & 120 & 5 & - \\
\hline [8] & MIMO & $\begin{array}{c}150 \times \\
80 \times \\
0.5\end{array}$ & $\begin{array}{c}3.5, \\
\text { LTE } 46\end{array}$ & 200,400 & - & $\begin{array}{l}62 \\
82\end{array}$ \\
\hline [9] & MIMO & $\begin{array}{l}74 \times \\
150 \\
\times 0.8\end{array}$ & $3.5,5.8$ & 200,150 & - & $\begin{array}{l}55 \\
70\end{array}$ \\
\hline [10] & MIMO & $\begin{array}{c}50 \times 50 \\
\times \\
1.6\end{array}$ & 3.5 & 400 & 4.2 & - \\
\hline $\begin{array}{c}\text { Our } \\
\text { Work }\end{array}$ & $\begin{array}{c}\text { Single } \\
\text { Element } \\
\text { MPA }\end{array}$ & $\begin{array}{c}34 \times 28 \\
\times 1.6\end{array}$ & 3.5 & 400 & 4.7 & 74 \\
\hline
\end{tabular}

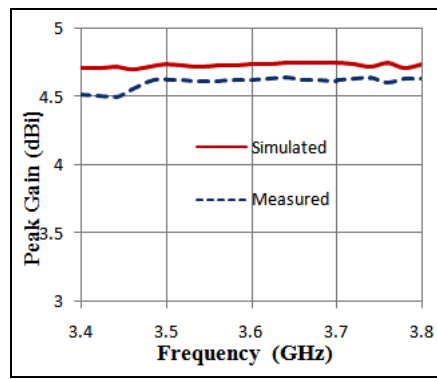

(a)

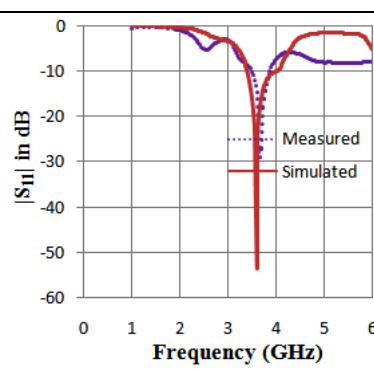

(b)
Fig. 11 (a) Simulated and measured gain (dBi) vs. frequency for proposed antenna; (b) Simulated and measured S-parameter for the proposed antenna.

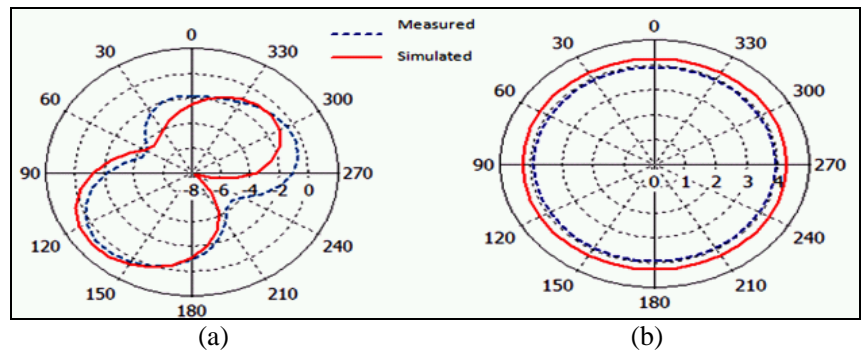

Fig. 12. Simulated and measured radiation pattern at $3.6 \mathrm{GHz}$ for the proposed antenna: (a) E-plane; (b) H-plane.

\section{CONCLUSIONS}

The design, optimization, and fabrication of a hand-pump shape microstrip patch antenna for sub- $6 \mathrm{GHz}$ future $5 \mathrm{G}$ applications is reported in this paper. The antenna 
performance is studied with the help of $S_{11}$ parameter, radiation efficiency, gain, and radiation pattern. In order to achieve the desired $(3.4 \mathrm{GHz}-3.8 \mathrm{GHz})$ band with appreciable return loss for sub- $6 \mathrm{GHz} 5 \mathrm{G}$ applications, the slots are etched into the patch and the ground plane of the antenna. The geometry of antenna is optimized by employing various algorithms, such as Particle Swarm Optimization, Differential Evolution, Bat, and Artificial Bee Colony. Further, the proposed hand-pump shape Microstrip patch antenna is simulated and fabricated using the geometrical parameters obtained using $\mathrm{ABC}$ optimization technique because the statistical parameters and normalized cost value of the $\mathrm{ABC}$ algorithm are better proved than of the other algorithms. The total gain is positive (nearly $5 \mathrm{dBi}$ ) and stable over the whole operating frequency band. The radiation pattern of the proposed antenna is bidirectional broadsided (8-shaped) in the E-plane, whereas it exhibits the omni-directional pattern in the H-plane. These properties make it quite improvised for $5 \mathrm{G}$ sub- $6 \mathrm{GHz}(3.4 \mathrm{GHz}-$ $3.8 \mathrm{GHz}$ ) LTE $42 / 43$ band $5 \mathrm{G}$ applications. Furthermore, a comparison table (see Table is tabulated in Section VI, which shows that the radiation efficiency of a single element antenna is the same as or even better than of the reported $5 \mathrm{G}$ MIMO antenna for $3.5 \mathrm{GHz}$ band. The promising results allow the proposed antenna to be employed in the future sub-6 GHz 5G applications.

\section{REFERENCES}

[1] A. Osseiran et al., "Scenarios for $5 \mathrm{G}$ mobile and wireless communications: the vision of the METIS project", IEEE Communications Magazine, vol. 52, no. 5, pp. 26-35, 2014. DOI: 10.1109/MCOM.2014.6815890.

[2] 5G deployment below $6 \mathrm{GHZ}$. Nokia white paper, 2017. Online. [Available]: https://resources.ext.nokia.com/asset/201315

[3] O. M. Haraz, A. Elboushi, S. A. Alshebeili, and A. Sebak, "Dense dielectric patch array antenna with improved radiation characteristics using EBG ground structure and dielectric superstrate for future 5G cellular networks," IEEE Access, vol. 2, pp. 909-913, 2014. DOI: 10.1109/ACCESS.2014.2352679.

[4] K. Mak, K. So, H. Lai, and K. Luk, "A Magnetoelectric dipole leakywave antenna for millimeter-wave application", IEEE Transactions on Antennas and Propagation, vol. 65, no. 12, pp. 6395-6402, 2017. DOI: 10.1109/TAP.2017.2722868.

[5] D. J. Bisharat, S. Liao, and Q. Xue, "High gain and low cost differentially fed circularly polarized planar aperture antenna for broadband millimeter-wave applications", IEEE Transactions on Antennas and Propagation, vol. 64, no. 1, pp. 33-42, 2016. DOI: 10.1109.TAP.2015.2499750.

[6] D. HA and Y.B. Jung, "Wideband proximity coupled microstrip linear array design for 5G mobile communication", Microwave and Optical Technology Letter, vol. 59, no. 12, pp. 2996-3002, 2017. DOI: 10.1002/mop.30860.

[7] K. M. Mak, H. W. Lai, K. M. Luk, and C. H. Chan, "Circularly polarized patch antenna for future 5G mobile phones", IEEE Access, vol. 2, pp. 1521-1529, 2014. DOI: 10.1109/ACCESS.2014.2382111.

[8] Y. Li, C. Sim, Y. Luo, and G. Yang, "Multiband 10-antenna array for sub-6 GHz MIMO applications in 5-G smartphones", IEEE Access, vol. 6, pp. 28041-28053, 2018. DOI: 10.1109/ACCESS.2018.2838337.

[9] K. L. Wong, B. Lin, and B. W. Li, "Dual-band dual inverted-F/loop antenna as a compact decoupled building block for forming eight 3.5/5.8-GHz MIMO antenna in the future smart phone", Microwave and Optical Technology Letter, vol. 59, no. 11, pp. 2715-2721, 2017. DOI: 10.1002/mop.30811.

[10] S. Saxena, B. K. Kanaujia, S. Dwari, S. Kumar, and R. Tiwari, "MIMO antenna with built-in circular shaped isolator for sub-6 GHz 5G applications", Electronics Letters, vol. 54, no. 8, pp. 478-480, 2018. DOI: 10.1049/el.2017.4514.

[11] D. Liu, X. Gu, C. W. Baks, and A. Valdes-Garcia, "Antenna-inpackage design considerations for Ka-band 5G communication applications", IEEE Transactions on Antennas and Propagation, vol. 65, no. 12, pp. 6372-6379, 2017. DOI: 10.1109/TAP.2017.2722873.

[12] S. Hsu, K. Wei, C. Hsu, and H. Ru-Chuang, "A 60-GHz millimeterwave CPW-fed Yagi antenna fabricated by using $0.18 \mu \mathrm{m}$ CMOS technology", IEEE Electron Device Letters, vol. 29, no. 6, pp. 625627, 2008. DOI: 10.1109/LED.2008.920852.

[13] S. Saadat, H. Mosallaei, and E. Afshari, "Radiation-efficient $60 \mathrm{GHz}$ on-chip dipole antenna realised by reactive impedance metasurface", IET Microwaves, Antennas \& Propagation, vol. 7, no. 2, pp. 98-104, 2013. DOI: 10.1049/iet-map.2011.0622.

[14] A. Bagis, H. Senberber "ABC Algorithm Based PID Controller Design for Higher Order Oscillatory Systems", Elektronika ir Elektrotechnika, vol. 23, no. 6, pp. 3-9, 2017. DOI: 10.5755/j01.eie.23.6.19688.

[15] N. R. Khanna and J. Kaur, "Optimization of modified T-shape microstrip patch antenna using differential algorithm for $\mathrm{X}$ and $\mathrm{ku}$ band applications", Microwave and Optical Technology Letter, vol. 60, no. 1, pp. 219-229, 2017. DOI:10.1002/mop.30939.

[16] D. Karaboga, "An idea based on honey bee swarm for numerical optimization", Techn. Rep. TR06, Erciyes University, Eng. Faculty, Computer Engineering Department, 2005. Online. [Available]: https://pdfs.semanticscholar.org/015d/f4d97ed1f541752842c49d12e4 29a785460b.pdf

[17] R. Gopi, D. Mandal, R. Kar, and S. P. Ghoshal, “Opposition-based BAT algorithm for optimal design of circular and concentric circular arrays with improved far-field radiation characteristics", International Journal of Numerical Modeling: Electronic Networks, Devices and Fields, vol. 30, pp. 3-4, 2017. DOI:10.1002/jnm.2087.

[18] D. W. Boeringer and D. H. Werner, "Particle swarm optimization versus genetic algorithms for phased array synthesis", IEEE Transactions on Antennas and Propagation, vol. 52, no. 3, pp. 771779, 2004. DOI: 10.1109/TAP.2004.825102.

[19] D. Ustun and A. Akdagli, "Design of a dual-wideband monopole antenna by artificial bee colony algorithm for UMTS, WLAN, and WiMAX applications", International Journal of Microwave and Wireless Technologies, vol. 9, no. 5, pp. 1197-1208, 2017. DOI: $10.1017 / \mathrm{S} 1759078716001355$. 